\title{
The Content Analysis of the Research Papers on Language Learning Strategies
}

\section{Asst. Lec. Pola Tahseen Mohammed}

Department of English, College of Arts, Knowledge University, Erbil - Iraq

pola.mohammed@knowledge.edu.krd

Asst. Lec. Manaf Basil Raewf

Department of Banking, College of Administration, Cihan University, Erbil - Iraq

manafbasil@cihanuniversity.edu.iq

\section{ARTICLE INFO}

\section{Article History:}

Received: $23 / 5 / 2018$

Accepted: $3 / 7 / 2018$

Published: Fall 2018

Doi:

10.25212/lfu.qzj.3.4.34

Keywords:

Content analysis on

language learning,

strategies, Language

learning, trends,

Language strategies

\section{ABSTRACT}

This study aimed to analyse the recent trends of language learning strategies in English Language Teaching (ELT) domain. Understanding and effective utilization of these learning strategies is vital in ELT. Content analysis approach has been chosen in order to provide a better idea of strategies used for future researcher and academic practitioner involve in English language learning and teaching. Content analysis are the best way to provide a bigger picture of any research area. A (45) number of articles have been analysed to define criteria in the research. The findings provide a clear picture of research approach, sample size, participants' profile, analysis technique and data collection instruments adopted by previous authors from their papers conducted study on Language Learning Strategies (LLS).

\section{INTRODUCTION}

Learning strategies play an essential role in understanding of any information by students or learners. Unawareness in regards to these strategies and their utilization in lessons may lead learners to fall in lessons. Moreover, conducting research on learning strategies is considered to be the hardest jobs as direct observation and selecting an appropriate method is challenging (Ezat and Mehran, 2017). Language learning strategies 
are of great interest for English language learning teachers. These strategies can be credited to their search for the most effective ways to enhance their students' English learning skills. Due to the great variety and number of these strategies, it is often challenging for teachers to choose the right and most effective strategy that enhance and develop students' learning (Cohen and Macaro, 2007).

Language learning strategies are considered as actions of behaviors of learners that they use in order to make language learning easier, self-directed, interesting an and successful (Oxford, 1989). Stern (1983) in this regard further added that learning outcomes are usually influenced by the learning approaches and processes, while these processes are affected by internal characteristics and learning situations of learners (Mohammed and Thabit, 2015). O'Malley \& Chamot (1990) acknowledged that a wide range language learning provides a competitive framework of valuable categories of language learning strategies. Four larger categories of these strategies have been utilized by many theorists are: cognition, social, meta-cognitive and affective (Oxford, 1996).

According to Jing Liu (2010) studies conducted in domain of language learning strategies had a great significance. Though, this area might have plenty of researches and hold a much promise, however, there is still a lot more potential (Thabit and Mohammed, 2017). Therefore, this article aims to provide trends of papers published during past 30 years to analyse the strategies adopted in language learning researches.

\section{LITERATURE REVIEW}

There have been quite rare studies that emphasize on content analysis in international context of publications specifically done in English language learning strategies. LaBelle (2010) investigated the written and illustrated content of 33 books containing range of language learning strategies. In order to measure the study, LaBelle developed a coding tool check the how often each of 15 language learning strategies was represented. Findings indicated that 6 books out of 33 had good to excellent range of learning strategies in terms of written and illustration content.

Jing Liu (2010) summarized and reviewed the literature of previously done studies in context of language learning strategies. He also analysed the training models that point out the implications of language learning strategies to English language learners. He further investigated how to choose an applicable and effective language learning strategies based training model, which is beneficial both to ELT learners and teachers.

Woravut (2012) analysed 200 research publications to explore the difference between international and Thai researches in English Language Teaching (ELT). The publications included 100 researches published by ELT academics in Thailand in English language and 100 researches in international journals for the period from 2003 to 2007.

Hardan (2013) presented a general overview about language learning strategies, where he categorized his study as per research type and its classification. His objective was to help future researchers regarding the better use of language learning strategies, so they 
can have better understanding while performing future research. He used qualitative approach to present these classifications.

\section{METHODOLOGY}

To present the trends of research papers in English language teaching and learning domain content analysis approach has been used. Content analysis is an ideal approach for this study as it is effectively reviewed the variations of types and frequency of language learningstrategies (LaBelle, 2010). Neuendorf (2002) defined content analysis as a scientific tool and stated that it is not limited to variables types to be measured or presented. Likewise, Hsiu-Fang and Sarah (2005) stated that content analysis is widely used research approach. It consists of three different categories such as: collective, conventional and directive.

A number of 80 research papers in English language teaching and learning published between 2010-2018 years, were scanned in education context in this study. Articles have been gathered from research databases Elsevier, ScienceDirect, SpringerLink and GoogleScholar specially. All selected articles later should match with the following criteria:

- The articles should be a research conducted in ELT domain

- $\quad$ The articles should be published between 2010 and 2018

- The articles should be publically available

Many articles have been excluded due to not meeting with our research criteria. Eventually only 45 articles have been finally included to present the research trends of language learning strategies in ELT. Later, content analysis has been performed in terms of published year, research title with more emphasize on methodology adopted by researchers.

Research Questions: The study is ultimately answered following research questions:

1. What research topics have been used in defined years?

2. What sampling technique, sample size and audience profiles were considered?

3. What research approach and data collection instruments have been used? 


\section{FINDING AND RESULTS}

The research classifications done in this study have been taken from Sozbilir and Kutu (2008). Thus, the study has been distributed based on research topic, design, research method, published year, data collection approach, sample size, population, data analysis technique and research design.

Figure 1 below shows the distribution of studies based on research topics covered during the period of 2010 and 2018. In regards of distribution, topics have been categorized in different terms, for example ELT studies that specifically focuses on teaching process, method, effectiveness or models have been summed up in title "Teaching", while studies emphasizing on learning been aligned under learning section.

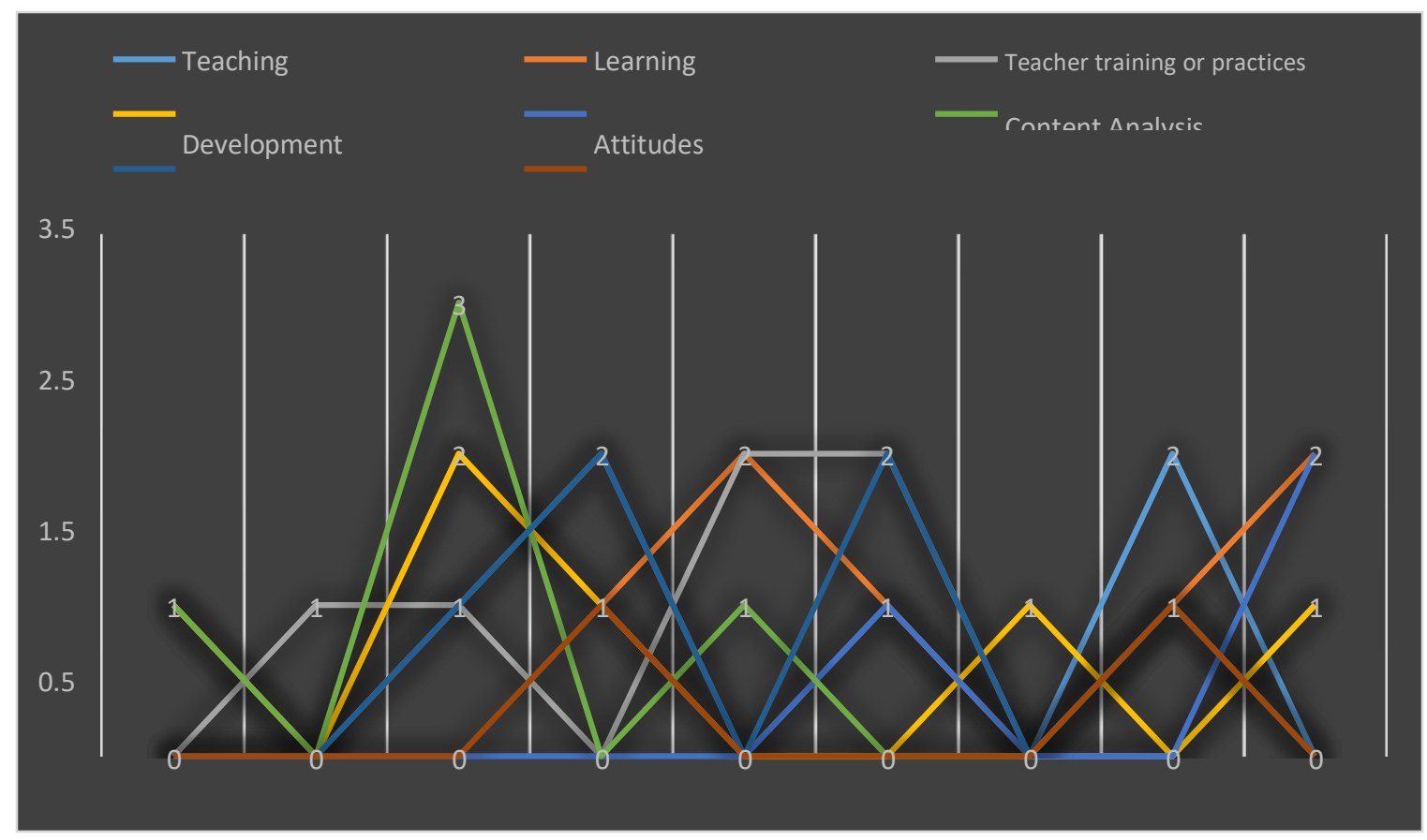

Fig. 1: Research distribution based on topics

Thus, as presented in Figure 1 above, a total number of 6 studies emphasized on teaching. One study has been conducted in 2012, Two studies in 2013, one in 2015 and two in 2017. In regards of learning, a higher number of 10 studies have been found in this area. One study in 2010, two in 2012, one in 2013, two in 2014, one in 2015 and 2017 and two in 2018 have been discovered. In regards of teachers' practices or training a total number of 7 studies have been identified. A similar number of 7 studies contributed in development area of ELT. A total number of 3 studies, one was published in 2015 and the ot her two were published in 2018 on students or teachers' attitude have been found.

Content analysis also remained a common research topic in ELT. A number of 5 studies have been identified on this topic. The year 2012 had higher number (3) ofstudies. 
Six studies focusing on technology topic particularly in ELT area have been discovered. All studies have been found between years 2013 and 2017.

Table1: Research distribution based on research design

\begin{tabular}{|c|c|c|}
\hline Research Design & $\boldsymbol{N}$ & \% \\
\hline Quantitative & 25 & 56 \\
\hline Qualitative & 12 & 27 \\
\hline Mixed-Method & 8 & 18 \\
\hline Total & 45 & $100 \%$ \\
\hline
\end{tabular}

Table 1 above represents the distribution of selected studies in terms on the research design. Thus, as showed, 25 (56\%) studies adopted quantitative research design, $12(27 \%)$ studies were based on qualitative design, while only $8(18 \%)$ studies were based on mix-method research design.

Table 2: Research distribution based on data collection instruments

\begin{tabular}{|c|c|c|}
\hline Data Collection Instruments & $\boldsymbol{N}$ & $\%$ \\
\hline Observation & 13 & 16 \\
\hline $\begin{array}{c}\text { Interview (Structured, semi- } \\
\text { structured) }\end{array}$ & 15 & 11 \\
\hline Questionnaire & 23 & 17 \\
\hline Documents (papers, textbooks, etc) & 5 & 5 \\
\hline Other & 7 & 7 \\
\hline
\end{tabular}

The studies in the findings were further distributed in terms of their data collection instruments. The results of these distributions are shown above in Table 2, which illustrates that 13 studies used observation approach as data collection tool, fifteen (11\%) studies were based on interviews for data collection, and a higher number of (23) studies used questionnaire as their research tool in gathering data. The finding also showed that, 5 studies were conceptual that used document such as papers, textbooks or other documents for data gathering, while five studies been found with different research tools, for example they either used two or multiple data collection tools or any theoretical framework or model to collect data from audience. 
QALAAI ZANIST SCIENTIFIC JOURNAL

A Scientific Quarterly Refereed Journal Issued by Lebanese French University - Erbil, Kurdistan, Iraq

Vol. ( 3 ), Issue ( 4 ), Fall 2018

ISSN 2518-6566 (Online) - ISSN 2518-6558 (Print)

Table 3: Research distribution based on sample size

\begin{tabular}{|c|c|c|c|}
\hline \multicolumn{1}{|c|}{} & $\boldsymbol{N}$ & $\mathbf{\%}$ \\
\hline \multirow{4}{*}{ Audience Type } & Students & 22 & 49 \\
\cline { 2 - 4 } & Faculty & 5 & 11 \\
\cline { 2 - 4 } & Teachers & 15 & 33 \\
\cline { 2 - 4 } Gender & Others & 3 & 7 \\
\cline { 2 - 4 } & Male & 2 & 4 \\
\cline { 2 - 4 } & Female & 3 & 7 \\
\hline
\end{tabular}

The papers were further distributed based on the sample size. As shown in table 3, most of the studies targeted students as their samples. Hence, a total number of 22 (49\%) researches chose students as a sample. Fifteen (33\%) studies focused on teachers for their research data collection and findings. While, only $5(11 \%)$ found targeting faculty members or staff of the school, and 3 studies have been seen with different type of audience for example, both students and teachers, faculty staff and teachers and any random individuals (neither students, teachers nor faculty).

Moreover, in regards to gender as shown, a higher number of studies has both male and female participants, while only two studies has on male, and 3 studies on female participants.

\section{DISCUSSION}

The results have been analyzed in various categories. Results revealed a high number of studies focused on English language learning topic and 2012 with many researches done in ELT as compare to the rest of the years. In terms of research design, the quantitative was the most used one as compare to qualitative and mix-method research design. In regards of data collection tools 15 studies used interviews, 13 used observations, and 23 studies used questionnaire as their research tool. Moreover, in respect to sample size $90 \%$ studies had both male and female gender, whereas they included higher number of students as participants, compared to teachers and faculty members.

The findings also revealed that learning strategies mostly describes the pedagogical context. Though, when comparing all these studies it contrasts in terms of their strategies and design, research method and data collection approach. There were not many studies that specifically targeted the learning strategies. However most of the studies were based on experimental researches. Some studies focused on content analysis or concept based researches, while most of them choose a quantitative approach where they involved research participants to observe their views and analyzed data statistically. 


\section{CONCLUSION}

The study emphasized on presenting the recent trends of language learning strategies adopted by previous researches. A number of 45 articles taken into account to achieve study objectives. All of the research articles were specifically chosen in ELT area. So content analysis approach has been used in order to present a bigger view of these researches. The content analysis makes replicable and valid inferences from content or texts in context of their use. Each research article has been classified based on proposed approach. Thus, studies distribution has been done in terms of their topic, publication year, sample and sample size, research method, data collection and analysis approach.

Eventually, the study presents the current trends in English language teaching area based on results analysed for past 9 years' studies. Study provides a brief summary of these researches which explores the strategies adopted by previous researches. The results of the study contribute to the future researchers and academician involve in English language teaching field. 


\section{REFERENCES:}

Cohen, A. D., and Macaro, E. (2007). Language learner strategies: 30 years of research and practice. Oxford: Oxford University Press.

Ezat, A. K., and Mehran M. (2017). Investigating language learning strategies in ELT. Proceedings of the Fourth International Conference on Language, Discourse and Pragmatics, 8(23). 210-220.

Hardan, A. A. (2013). Language Learning Strategies: A General Overview. Social and Behavioural Sciences. 106, 712-1726.

Hsiu-Fang Hsieh, and Sarah E. Shannon (2005). Three approaches to qualitative content analysis. Qualitative Health Research. 15(9), 1277-1288.

Jing Liu (2010). Language learning strategies and its training model. International Education Studies. 3(3), 100-104.

Krippendorf, K. (2004). Content analysis: An introduction to its methodology (2 ${ }^{\text {nd }}$ ed.). Thousand Oaks, CA: Sage Publications, Inc.

LaBelle, J. T. (2010). Selecting ELL textbooks: A content analysis of L2 learning strategies. Journal of Language Teaching and Research, 1(4), 358-369.

Mohammed, P. T., and Thabit, Th. H. (2015). Evaluation the strategies of learning English as second language case study of Cihan university - Erbil, International Journal of Engineering Research and Management Technology, 2(4), 19-24.

Neuendorf, K. A. (2002). The content analysis guidebook. Thousand Oaks, CA: Sage Publications, Inc

O'Malley, J. M., \& Chamot, A. U. (1990). Language learning strategies in second language acquisition. Cambridge: Cambridge University Press.

Oxford, R. (1996). Language learning strategies around the world: Cross-cultural perspectives. Honolulu: University of Hawai'i Press.

Sözbilir, M. \& Kutu, H. (2008). Development and current status of science education research in Turkey. Essays in Education, Special Issue, 1-22.

Stern, H. H. (1983). Fundamental Concepts of Language Teaching. Oxford, England: Oxford University Press.

Thabit, Th. H., and Mohammed, P. T. (2017). Measuring the cost and benefit of learning English at private universities in Kurdistan, International Journal of Engineering Sciences \& Management Research, 4(8), 36-42.

Woravut, J. (2012). A content analysis of Thai and international research articles in ELT. Doctor of Philosophy Thesis, Macquarie University, Thailand. 